\title{
Traineeships - continuous learning and training in a work context
}

\author{
Filipe M.M. Raminhos ${ }^{1}$, M. M. Travassos Valdez ${ }^{1}$, C. Machado Ferreira ${ }^{1}$, F. P. Maciel Barbosa ${ }^{2}$ \\ ${ }^{1}$ Instituto Superior de Engenharia de Coimbra, Instituto Politécnico de Coimbra, \\ Coimbra, Portugal \\ \{fmm.raminhos@gmail.com; cmacfer@isec.pt; valdez@isec.pt\} \\ ${ }^{2}$ Faculdade de Engenharia, Universidade do Porto \& INESCTEC Porto \\ Porto, Portugal \\ $\{f m b @ f e . u p . p t\}$
}

\begin{abstract}
This work aims to describe the added value of the skills acquired during a Master's degree in Building Services Engineering taught at the Instituto Superior de Engenharia de Coimbra (ISEC) in the Departments of Electrical (DEE) and Mechanical Engineering (DEME). It is concerned with the integration of the student in the world of work, describing the framework of the various activities carried out during the internship.

The curricular internship led to the acquisition of professional experience in the area of projects within the framework of special technical installations, including lighting design in its various aspects. Several lighting design studies were developed either of interiors or exteriors and were extended to designs of bunkering stations, hospitals, post offices, hotels and homes in general. It also led to the acquisition of professional experience in the fields of electrical installations, telecommunications, fire safety in buildings and HVAC (Heating, Ventilation and Air Conditioning).

The trainee had to assume responsibilities, applying theoretical knowledge to practical contexts developing decision-making skills and overcoming the proposed challenges. The trainee had to follow the work of the technical teams and to observe on site the deployment of projects as they were being carried out. He was also able to check if the work was evolving according to plans, contact the architects, the building owners as well as the staff of companies in charge of other specialties. The trainee experienced the difference between analysing and studying a two dimensional blueprint or even photos, and observing the actual design details on site, sometimes not so noticeable on paper or on the computer. This allowed him to assimilate important information, and be actively involved as part of the team, one of the reasons why the trainee opted for an internship of this kind that contributed to a better understanding of certain concepts in these areas of engineering.
\end{abstract}

Keywords - Electrical Installations, Light Design, Special Technical Facilities, Traineeships

\section{INTRODUCTION}

Learning through internship is essential in engineering as practical courses are an important part of most curricula.

Trainees can acquire professional experience in the area of projects within the framework of: Special technical installations, Electrical installations, Telecommunications,
Fire safety in buildings, HVAC (Heating, Ventilation and Air Conditioning). It is the integration in the world of work. Education and training infrastructures are of paramount importance. Skills development can contribute to improve productivity and address the challenges faced by workers. Traineeships, education and jobs are effective means of bridging the gap between school and the world of work for young students. Students can acquire work experience along with technical and professional training, overcome the lack of work experience when trying to get a first job. Special and innovative programmes need to be further explored to meet the specific needs. Improved portability of skills helps students in obtaining employment adequate for their qualifications and expertise. So, innovative programmes are needed.

The progress of modern society requires that the current demands are met using competence translated into high level skills. The purpose of Higher Education Institutions (HEIs) is to provide students with the necessary qualifications for the labor market [1]. It is also important to stress that the gradual specialization of knowledge translates itself in specific areas of knowledge, neglecting in many cases the use of interdisciplinary resources, which are also relevant for the overall preparation of the students.

There must be a development and implementation of strategy structures and training systems accessible to all; mechanisms to motivate and support students in investing and developing skills; guarantee that the working conditions observe core labour standards and occupational safety and sustainable development; initiatives to advise on the value of the work and life experience while updating skills, in particular in new technologies and a development of innovative ideas in the use of alternative energies.

The key advantages are the improvement of quality and relevance of training, achieving greater flexibility of training delivery and assessment. They also provide a comprehensive and easily used national training product and encourages employers to see training as an attractive option. This development enhances competitive performance of enterprises and provides the skills and knowledge needed to perform effectively in the workplace. 
The departments of Electrical and Mechanical Engineering at the Instituto Superior de Engenharia de Coimbra (ISEC) teach a cycle leading to a master's degree (M.Sc.) in Building Services Engineering, in which 35\% of the total European credits (ECTs) of the cycle of studies refers to a project/dissertation/internship [2].

This paper describes a study carried out during a 9 month internship in a special technical projects company.

The internship is an important part of the master's degree (M.Sc.), linking theory and practice in an interdisciplinary way.

The trainee has to assume responsibilities, apply theoretical knowledge to practical contexts developing decision-making skills, overcoming the proposed challenges. He will be faced with new situations, to which it is essential to demonstrate responsiveness as well as initiative.

The trainee must be proactive in order to obtain practice and knowledge, essential to achieve the proposed goal. He acquired key competencies by collecting, analysing and organising information, communicating ideas and information, planning and organising activities, working with others and in teams, solving problems and using technology.

Thus, the internship can be regarded as the liaison connecting the three factors that play complementary roles: ISEC (providing education), the trainee (seeking knowledge) and the company (giving training).

\section{STRUCTURE AND ORGANIZATION}

The Bologna Degrees are in accordance with the European guidelines, resulting from the Bologna Agreement, and are based on the European reference and experience, the achievement of goals and defined skills [3].

ISEC focuses on providing a first cycle of studies, the Bachelor degree in Electrical Engineering, comprising a sixterm/three-year cycle with 180 ECTS, and combines a strong practical component with a solid theoretical background [3].

This is a landmark study that professional organizations recognize as offering individual capacity and responsibility to get involved in most engineering activities. The master's program consists of a four-term/two-year degree and a Specialization Course which integrates a set of curriculum units representing 65\% (78 ECTS) of the total number of credits, and an internship/project/dissertation with a final report, representing the remaining 35\% credits (42 ECTS) [2].

The course subjects are divided by years, semesters, and corresponding ECTS in a total of 120, according to the contact hours for theoretical, theoretical and practical classes, laboratory, tutorials and seminar. Since this is a joint Master's degree of the departments of Electrical and Mechanical Engineering, the courses are divided by field of studies [2].

\section{Global OBJectives AND CASE StUdies}

Through the internship, the trainee acquired professional experience in projects in the area of special technical equipment, including light design techniques, in its various forms and many studies of light design, both interior and exterior, were developed. These studies were extended to projects of telecommunications, liquid fuel stations, hospitals, post offices, hotels and homes in general [4]. They also led to the acquisition of professional experience in electrical installations, telecommunications, fire safety in buildings and HVAC (heating, ventilation and air conditioning).

The trainee started by learning the process of operations of the company and its internal rules. At this stage he learned about organizational procedures transversal to all employees, such as the structure of documents in designing projects, which includes drawings and written documents, as well as drawing the required technical symbols. This was required to learn and adopt procedures for the design of professional and technical aspects using the AutoCAD program as a tool for the preparation of drawings blueprints [4].

The following step was the research on various aspects of the legislation, so that the trainee gets acquainted and understands the legal framework for low voltage electrical installations in the national electric system [5].

The light design studies began with a survey of the factors that define quality lighting, types of sites, technologies used, particularly with regard to lamps, ballasts and control systems, by contacting project managers of specialized light design companies in order to obtain a technical support on the materials and features of different brands. The development of models and their simulation was initiated with Dialux software program, in which the trainee already had some technical/practical knowledge [6-7]. The curricular unit of Electrical Installations and Lighting design provided important input for the progression in the work context.

In a second phase, and by imperatives of the development of certain projects, the trainee had to start a thorough understanding and handling of Relux simulation program, of which he had no previous knowledge. This learning has proved to be very useful for future projects, as the trainee can now demonstrate capacity and versatility in handling multiple programs in this area [7-8]. He also had the opportunity to work on various national and international projects, being involved in conducting and participating in over 30 projects, which will be an asset to his career [4].

The design of electrical and telecommunication stations for liquid fuels and post office facilities with specific legislation demonstrate the extent of activities undertaken, as it is the case of gas stations, or specific equipment needed in post office shops (see Fig.1).

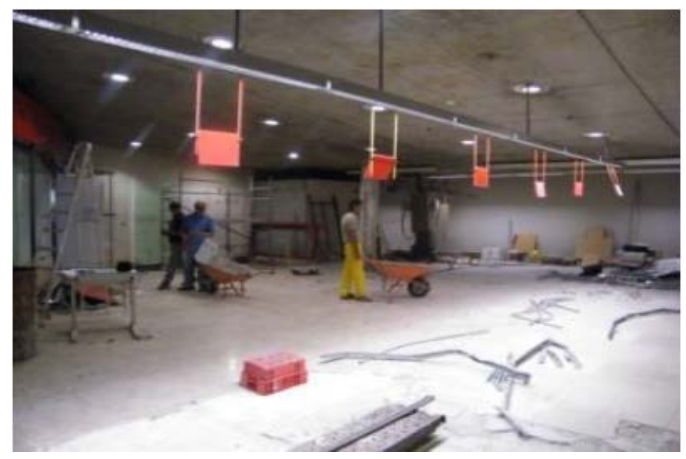

Fig. 1 Electrical installations of a post office with implementation of lighting design 
Liquid fuel supply stations have very specific and restrictive legislation and limitations in electrical terms. Since there is a high risk of explosions, and to ensure the protection of people and property against electrical shocks, it is necessary to install a land system in the buildings, which allows the flow of fault currents through the differential protection devices.

The trainee had to take responsibility and apply concepts that he studied in subjects such as Electrical Installations and Analysis of Electrical Systems, in practical situations, developing capacities of decision to overcome the various challenges. During the probationary period, the possibility of monitoring some projects with the technical teams in order to visualize in situ the deployment of the projects was also an added value (Fig.2).

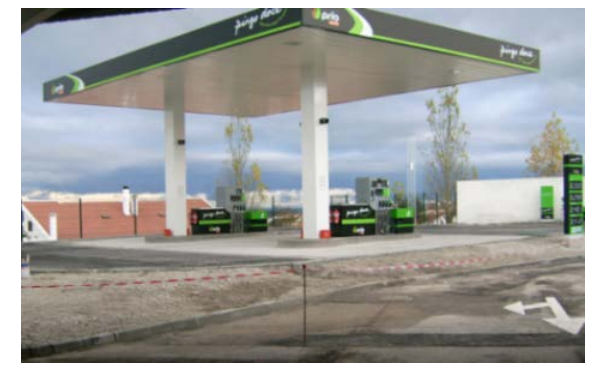

Fig. 2 Picture of the course of work of a liquid fuel gas station

The trainee could also determine whether the work was developed according to the plans, therefore monitoring progress, liaising with architects, project owners as well as staff of other agencies. The trainee experienced this way the difference between having only the perception of buildings/works, analyzing and studying a blueprint in two dimensions or even photos, and actually seeing the construction details, not so perceptive sometimes on paper or computer [4]. The development of more than 20 studies of light design had as methodology the verification and sizing of lighting interior environments that meet the standards recommended by the European Standard EN 12464-1 and EN 15193 [9-12].

The analysis of lighting, quantity and distribution, was made using graphical calculation methods, built in scale simulation model, in spite of the limitations regarding the appropriate computational equipment requirements, the theoretical assumptions needed by the trainee, and the limitation of project delivery.

One of the projects was the Mbanza hospital in Angola (Fig.3). The graphical environment was fully characterized with shapes, materials, colors, lamps and luminaires specified, as it will be implemented in reality to obtain a simulated lighting. All areas were targeted in the study, from the delivery room to the corridors, wards and operating rooms, etc.

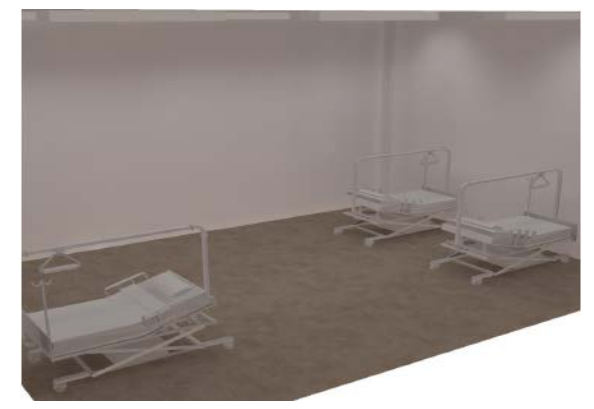

Fig. 3 3D rendering of the ward of the Mbanza Hospital, Angola

Fig. 4 shows the blueprint of the hospital electrical installations with the implementation of enlightenment obtained from the simulations of the lighting design.

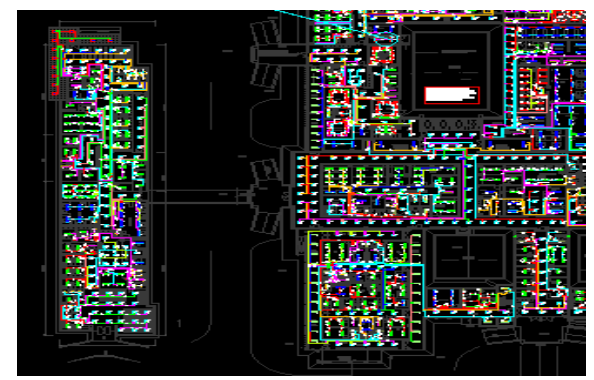

Fig. 4 Blueprint of hospital electrical installations with implementation of lighting design

The trainee was responsible for the direct choice of equipment presented as lighting solutions for the hospital, by contacting several project managers of lighting brands, conducting several meetings vis-à-vis, essential to demonstrate responsiveness, as well as initiative, being proactive so that, in the end, he could get the best equipment solutions for the project and the client.

Another task was the study and handling of the Relux lighting simulation program for the "Torres do Carmo" project in Angola. In commercial and residential-type buildings the lobby function is to take inside some of the outdoor environment, normally through natural lighting in the areas intended for circulation. First impressions count a lot, being essential to highlight this area with a welcoming environment (Fig. 5). Also see the Gourmet area (Fig. 6).

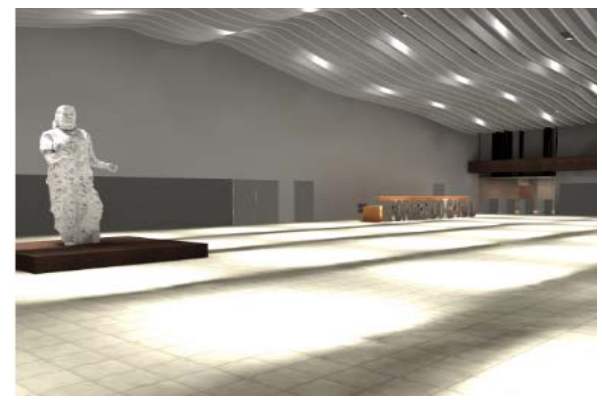

Fig. 5 3D rendering of the lobby area of “Torres do Carmo”, Angola 


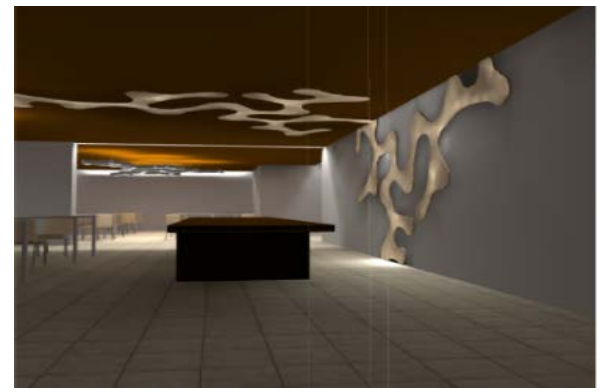

Fig. 6 3D rendering of the Gourmet area of "Torres do Carmo”, Angola

In addition to interior studies, exterior lighting design projects of great complexity in 3D buildings and their lighting design solutions were also carried out.

Fig. 7 is a 3D rendering of the fortress of Sesimbra, Portugal with its intricate features, held in Dialux with various design details that were difficult to project.

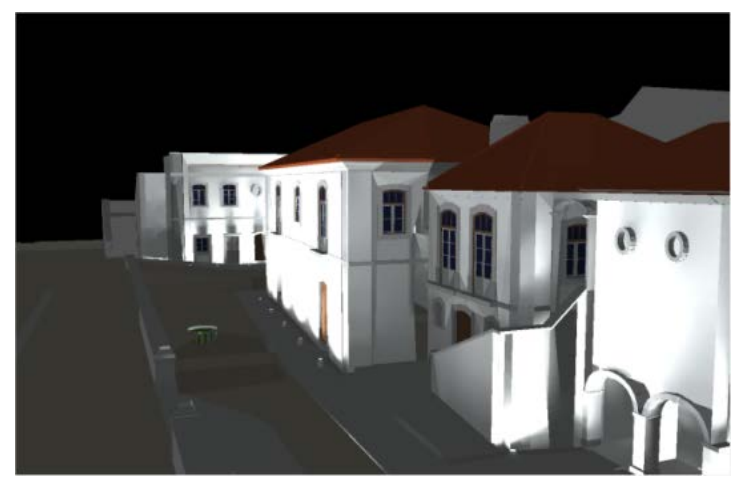

Fig. 7 3D view rendering of the façade of the fortress of Sesimbra, Portugal

The trainee was responsible not only for the electrical installations, but also for telecommunications, intrusion detection and security against fires (fire detection and others). In the field of electrical installations, he was responsible for lighting solutions listed in this case study. A 3D model of the entire exterior of the Fortress was built in Dialux, with 3D graphic results, which greatly contributed to the validation of the proposed equipment.

Another project of exterior lighting design was the refurbishment of the historic center of Vila Real de Santo António, Marquês de Pombal square (Fig. 8).

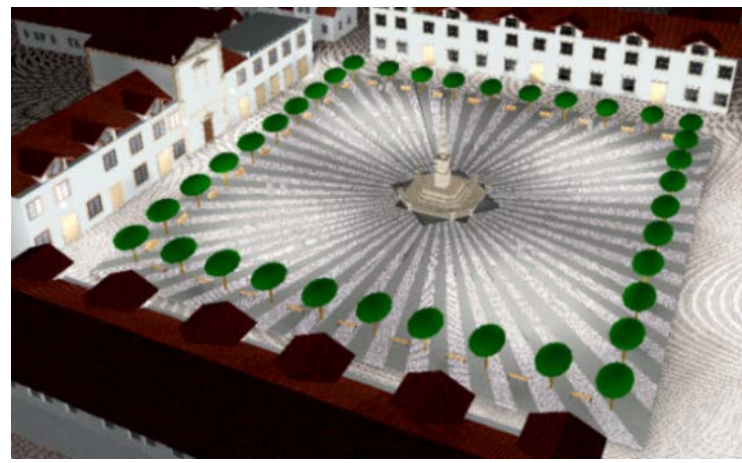

Fig. 8 3D rendering, of the square in Vila Real de Santo António, Portugal
A more comfortable environment was created highlighting the existing installations, the Church and the pillory.

Fig. 8, is a 3D rendering of the square held in Dialux, once again of great complexity with constructive details difficult to design, so as to obtain reliable results. This project aimed not only the correct lighting of path areas, but also the creation of a pleasant scenic space for the various users. It was not an easy study due to several problems, such as indexes of protection of light fixtures, or heating problems.

\section{CONCLUSIONS}

This internship expanded the horizons and tested the limitations and difficulties in applying theory to real cases. Thanks to the teachings and experience that have been transmitted by the various professionals, it was possible for him to apprehend many important details, either in the preparation of projects or on a visit to the sites. The trainee had the opportunity to work on several international projects.

The main objective of this internship was to acquire professional experience in the area of design and construction in its various aspects. This objective was reached by carrying out activities similar to those performed by professionals, who kindly provided their help and know-how in the orientation stage, contributing to the integration in the world of work, forcing him to take responsibility, apply theoretical knowledge in practical situations, develop capacities of decision and overcome challenges.

The trainee had the opportunity to follow the work of the technical teams in an asset. It allowed him to observe on site the deployment of projects as they were being carried out. He experienced the difference between analyzing and studying a two dimensional blueprint and observing the actual design details on site, assimilating important information, and becoming actively involved as part of the team.

The end of the internship ended with the integration of the trainee in the company.

\section{REFERENCES}

[1] Instituto Superior de Engenharia de Coimbra. Dossier da proposta do Mestrado em Instalações e Equipamentos Em Edificios. - Coimbra, Portugal, 2006. (in portuguese).

[2] Plano de estudos do ciclo de estudos conducente ao grau de mestre em Instalações e Equipamentos em Edifícios. Portugal, 2009. (in portuguese).

[3] Law on the Bases of the Education System // Decree-Law n ${ }^{\circ} 49 / 2005$, 30 of August, and Decree-Law n ${ }^{\circ}$ 74/2006, 24 of March. Law ${ }^{\circ}$ 62/2007, 10 of September. 2a series $-n^{\circ} 162-21$ of August 2009, Dispatch n ${ }^{\circ} 130098 / 2009$.

[4] CIE 171:2006: "Test Cases to Assess the Accuracy of Lighting Computer Programs”, ISBN 9783901906473. 2006

[5] CEN - European Committee for Standardization, "EN12464-1: Ligh and Lighting - Lighting of Work Places - Part 1: Indoor Work Places”, European Standard Ref. No EN 12464-1:2002, Brussels, Belgium, November 2002.

[6] Z. Feng, Y. Luo, and Y. Han. "Design of LED freeform optical system for road lighting with high luminance/illuminance ratio”. Optics Express. 22020-22031. 2010.

[7] Filipe M.M. Raminhos, M. M. Travassos Valdez, C. Machado Ferreira F.P. Maciel Barbosa, "Energy Efficiency In Artificial Light Design Using Different Computational Simulation Tools”, ICECE’2011 - VII International Conference on Engineering and Computer Education, 
September 25-28, 2011, Guimarães, Portugal, pp.109-114, (ISBN:97885-89120-98-2) \& (ISBN: 978-85-89549-94-3).

[8] Shailesh, K.R.; Raikar, T. S.: "Application of RELUX Software in Simulation and Analysis of Energy Efficient Lighting Scheme”, International Journal of Computer Applications (0975 - 8887), Volume 9- No.7, November 2010.

[9] CEN - European Committee for Standardization, "EN15193: Energy performance of buildings - Energy requirements for lighting”, European Standard Ref. No EN 15193:2007, Bruxelas, Bélgica, September 2007.

[10] CIE 171: "Test Cases to Assess the Accuracy of Lighting Computer Programs”, ISBN 9783901906473. 2006.

[11] Xu Yu, Yuehong Su, Xin Chen "Application of RELUX simulation to investigate energy saving potential from daylighting in a new educational building in UK”, Energy and Buildings, Volume 74, May 2014, Pages 191-202, Elsevier, 2014.

[12] Yuanyi Chena, Junjie Liua, Jingjing Peia, Xiaodong Caoa, Qingyan Chena, Yi Jiangb, "Experimental and simulation study on the performance of daylighting in an industrial building and its energy saving potential”, Energy and Buildings, Volume 73, April 2014, Pages 184-191, 2014. 